\title{
I. CENTROAMÉRICA EN LAS CORTES DE CÁDIZ
}

JORGE MARIO GARCÍA LAGUARDIA

Profesor de la UNAM

(México) 


\section{SUMARIO}

I. Las Cortes de Cádiz y la Constitución.-II. Opinión del AyunTAMIENTO DE GUATEMALA SOBRE CONVOCATORIA A CORTES.III. Representacion americana en Cortes. Los diputados por la Capitania General de Guatemala. Proceso de elección.-IV. Los DIPUTADOS SUPLENTES.-1. Elección y legitimidad. 2. Actuación de los diputados electos. V. El DIPUTADO PROPIETARIO POR GUATEMALA, DON ANTONIO DE LARRAZABaA. 1. Labor parlamentaria. 2. Las instrucciones al diputado. 3. Destino final del diputado Larrazábal y de los documentos. VI. EL RESTO DE LA DIPUTACIÓN CENTROAMERICANA.-VII. VISION GENERAL.-REFERENCIAS BIBLIOGRÁFICAS. 
Revista de Derecho Político, núm. 33, 1991, pp. 367-389

\title{
I. CENTROAMÉRICA EN LAS CORTES DE CÁDIZ
}

\author{
POR \\ JORGE MARIO GARCIA LAGUARDIA * \\ Profesor de la UNAM
}

(México)

\section{LAS CORTES DE CÁDIZ Y LA CONSTITUCIÓN DE 1812}

Todavia, durante el régimen colonial, un antecedente de gran importancia para nuestro Derecho constitucional y el régimen político que se adopta después de la independencia es la Constitución de Cádiz, que se promulgó en el año de 1812 en esa ciudad española y que estuvo vigente varios años en el país, y con base en la cual se produjeron nuestras primeras experiencias electorales.

Su elaboración debe vincularse estrechamente a los sucesos españoles de 1808 y a la invasión napoleónica. La opinión general española estuvo contra Napoleón, y al encontrarse el país sin guía ni dirección, acéfalo el trono, se organizó popular y localmente contra los franceses, y surgieron juntas locales y provinciales, algunas más importantes, como la de Sevilla, que se autodenominó Suprema de España e Indias, y todas ellas, finalmente, se refundieron en la Junta Central.

Ésta decidió dar participación a las provincias de América en su seno, posiblemente como una respuesta a los cuantiosos donativos que ellas enviaron a la Península. Por Decreto de 22 de enero de 1809 se declaró que no eran propiamente colonias sino parte integrante de la Monarquía y se les instaba a que enviaran un representante por cada uno de los virreinatos de Nueva España, Perú, Nueva Granada, Buenos Aires y cada una de las Capitanías Generales de Cuba, Puerto Rico, Chile, Venezuela y Guatemala.

* Profesor del Instituto de Investigaciones Jurídicas de la Universidad Nacional Autónoma de México, Secretario del Comité Directivo del Instituto Iberoamericano de Derecho Constitucional. 
Así se realizaron las primeras elecciones de nuestra historia, con base en un sistema muy complicado y se designó a Manuel José Pavón, que por la dinámica de los acontecimientos no pudo incorporarse a la Junta (Archivo General de Indias, 1812, Audiencia de Guatemala, Leg. 493; Boletín del Archivo del Gobierno, 1938 a, núm. 3. En adelante se identifican con sus siglas).

La Junta Central fue sustituida por un órgano más concentrado, la Regencia, de cinco miembros, y superadas diferencias se convocó a Cortes por decreto de junio de 1810 , y en septiembre, finalmente el cuerpo constituyente se instaló, declarando en su primera disposición que la soberanía residía esencialmente en la Nación. Y más tarde en una frenética actividad legislativa dictó múltiples disposiciones institucionalizando los puntos programáticos del liberalismo: libertad de imprenta, abolición de la Inquisición, supresión del tributo del voto de Santiago, incorporación a las nación de todos los señorios jurisdiccionales, abolición de los dictados de vasallo y vasallaje, supresión de pruebas de nobleza, abolición de mitas y repartimientos de indios, libertad de industria, libre comercio... Aquella noche, la del 24 de septiembre de la sesión inaugural, «aunque casi nadie - aun entre los protagonistas- se diese cuenta, habia caido en España el Antiguo Régimen» (Cfr. COMELLAS, 1962, pág. 77).

Una Comisión específica presentó el Proyecto de Constitución con un importante Discurso Preliminar, que fue discutido por espacio de ocho meses y el 19 de marzo de 1812 la Constitución fue promulgada. En tres años y 1.800 sesiones, este cuerpo constituyente rompió el andamiaje de la añeja monarquía española. Si en el propio documento, en términos generales se limitaron a plantear la reforma de tipo político, en una fértil emisión de decretos, pusieron el acento en la reforma social y económica. Adopción de la teoría fisiocrática, abandono de la organización estamental y sustitución de la vieja monarquía absoluta basada en el derecho divino de los reyes, son las realizaciones del proceso revolucionario de Cádiz. $Y$, naturalmente, la elaboración de la primera Constitución para España y sus colonias.

El constitucionalismo es la primera y más importante decisión política que se le puede atribuir a Cádiz. Se redactó la primera Constitución y la más amplia de todas: 384 extensos artículos. Resulta del texto, la intención de sustituir todo el andamiaje politico y social; es redactado con una precisión matemática, que en los capítulos del registro electoral se hace evidente; y se enmarca dentro de la corriente de racionalización del poder típico de la época: se pretendía en un esfuerzo mental muy del siglo XVIII, abarcarlo, preverlo todo. Hasta la división esquemática de su articulado en diez títulos se nos presenta como algo totalmente acabado, como la obra de un solo artífice. $Y$ tan seguros estaban los constituyentes de su obra, que concibieron una Constitución casi pétrea, pues se prohibia su modificación por un periodo de ocho años después de promulgada. $Y$ en un sentido programático, recogió toda la plataforma liberal en su articu- 
lado. La revolución española quedó ahí escrita. De ahí en adelante se podría gobernar por «máximas», como decían los autores del Discurso Preliminar. Y por eso la Constitución de Cádiz devino en un mito del constitucionalismo español, en el punto de referencia de todas las posteriores disputas, hasta las más reciente (Cfr. GARCÍA LAGUARDIA, 1967).

\section{OPINIÓN DEL AYUNTAMIENTO DE GUATEMALA SOBRE CONVOCATORIA A CORTES}

La lucha por una adecuada representación de las provincias americanas se inicia desde el año 1809. En respuesta a una consulta general dirigida a personalidades y órganos de gobierno, entre ellos los ayuntamientos, el de Guatemala envía una amplia representación en la que fija sus puntos de vista: defensa de la vieja doctrina medieval de los derechos naturales y soberanía, cuidadosamente aprendida por los integrantes del ayuntamiento en la Universidad de San Carlos durante el periodo de su reforma ilustrada; oposición a la reducción de miembros de la Junta General en un Consejo de Regencia, que limitaria aún más la participación americana, pidiendo incluso que si uno solo fuera el representante americano, lo fuera el diputado Pavón, del ayuntamiento de Guatemala; y fundamentalmente que si se trataba de dictar leyes fundamentales y modificar la forma de gobierno, esto no se hiciera sin la presencia de sus diputados; es decir, oposición a Cortes constituyentes, sin representación legítima de Guatemala. Posición que se reitera en otras comunicaciones posteriores y por el propio diputado Larrazábal al integrarse a la Asamblea (Cfr. GARCíA LAGUARDIA, 1969, que publica el documento completo; también, JIMÉNEZ DE GREGORIO, 1936, y ARTOLA, 1959; Archivo Histórico Nacional, 1810, Sección de Estado, Legajo 20, Letra L, Expediente 7).

III. REPRESENTACIÓN AMERICANA EN CORTES. LOS DIPUTADOS POR LA CAPITANIA GENERAL DE GUATEMALA. PROCESO DE ELECCIÓN

Antes de disolverse la Junta Central, manifestó expresamente que las provincias de ultramar tendrian representación en las Cortes y dictó algunas providencias para una presencia supletoria mientras llegaran los diputados electos. $Y$ el Consejo de Regencia, nuevo órgano concentrado de gobierno - cinco miembros de los cuales uno era americano-, en de- 
creto de 14 de febrero de 1810 reglamentó la forma de elegir a los diputados. Fijaba en 30 el número de suplentes, y señalaba que los propietarios serian de los Virreinatos de Nueva España, Perú, Santa Fe y Buenos Aires y de las Capitanías generales de Puerto Rico, Cuba, Santo Domingo, Guatemala, Provincias Internas, Venezuela, Chile y Filipinas. Los diputados serían uno por cada capital cabeza de partido de estas diferentes provincias. Y fijaba el procedimiento interno de la elección: se haría por el ayuntamiento de cada capital, nombrándose tres naturales de la provincia de calidades especiales, sorteándose después uno de los tres, y el que saliera a primera suerte sería el diputado en Cortes. El ayuntamiento debería entregar poderes e instrucciones a su diputado sobre objetivos de interés general y particular que debería promover en las Cortes, y se dirigiria a la isla de Mallorca, donde se reunirían todos los representantes americanos, a la espera de la reunión de Cortes. Los gastos correrían por cuenta de los ayuntamientos.

Las noticias de la convocatoria fueron recibidas en Guatemala con gran beneplácito. El capitán general hizo conocer el decreto respectivo así como el Manifiesto a los españoles americanos con fecha 4 de junio de 1810 (AGI Audiencia de Guatemala, Legajo 493), y el ayuntamiento de la capital se apresuró a cumplir con lo ordenado y se reunió el 24 de julio para proceder a la elección del diputado por la capital. Salieron favorecidos Antonio Juarros, José Aycinena y el canónigo Antonio Larrazábal, que era vicario capitular y gobernador del arzobispado, y hecho el sorteo previsto salió electo el último de ellos. Este acto se celebró con gran júbilo, oficiándose un Te Deum en la catedral, a la usanza de la época, con participación de las altas autoridades, y se hicieron grandes demostraciones de regocijo popular (Cfr. "Acta de elección del diputado", BAGG, 1938c con, año III, núm. 4, págs. 475-478).

El Capitán general cursó el decreto a las diversas provincias y realizadas las elecciones salieron designados los siguientes diputados: Licenciado Sebastián Esponda, por Chiapas, quien por haber fallecido fue sustituido por el sacerdote secretario del obispo, Mariano Robles Domínguez de Mazariegos; Ignacio Ávila, por El Salvador; abogado Francisco Morejón, por Honduras; abogado José Antonio López de la Plata, por Nicaragua, y presbítero Florencio del Castillo, por Costa Rica.

\section{LOS DIPUTADOS SUPLENTES}

\section{Elección y legitimidad}

En virtud de la dificultad para que los diputados americanos electos llegasen a Cádiz y la presión por la representación americana, se resolvió 
que se nombraran diputados suplentes en número de 30 , escogidos entre los oriundos de esas provincias que residieran en la Península.

La elección de suplentes inicia en forma orgánica la fundamental discusión sobre la igualdad de representación americana y española. En el mismo acto de la elección de diputados, los americanos votantes reclamaron por el escaso número de suplentes y por el hecho de que los propietarios no estuvieren en proporción a los habitantes de las colonias como sí lo estaban en el caso español. Redactaron un escrito, un verdadero voto razonado, explicando que procedian a la elección de suplentes para no retrasar la reunión de Cortes, pero no se considerará en forma definitiva el número de diputados, ya que en su oportunidad debería corresponder, como a España, un número de representantes proporcional a la población (Cfr. PÉREZ GHILOW, 1981, págs. 61-65, 70-72, y KING, 1953).

Y también en las colonias se puso a discusión la legitimidad de esta representación. Fuera de señalar su calidad temporal, se les negó verdadera autoridad y representación, sobre todo en las regiones en donde había comenzado el movimiento emancipador. Que no fue el caso de Guatemala, donde los patriotas todavía creían encontrar un vínculo con la metrópoli a través del movimiento progresista que significaban las Cortes.

Todavia después que los suplentes habian abandonado la Asamblea, sustituidos por los propietarios, el tema se volvía a poner en el tapete por el diputado por la capital Antonio Larrazábal, «famoso diputado" (Cfr. RAMOS, 1962, pág. 474), quien argumentó que los suplentes no podían representar a la provincia por no tener las instrucciones y conocimientos del país adecuados y por su larga ausencia de su provincia. Sin embargo, es necesario hacer notar que el estado de ánimo que privaba en la Capitanía General, la integración del ayuntamiento de la capital y la personalidad de los suplentes designados, coincidieron para lograr una relación cordial durante la representación temporal.

\section{Actuación de los diputados electos}

Los diputados electos fueron dos hermanos, militares ambos, don Andrés - capitán de navio-y don Manuel de Llano - coronel de artillería-, quienes habian nacido en Guatemala, hijos de un funcionario español, el contador real. Por razones de estudios y negocios se habian trasladado a la metrópoli y vivían en Cádiz en el momento de su elección.

Don Andrés de Llano, dedicado a sus actividades comerciales, no tiene una participación destacada en la Asamblea, donde sus ausencias son notorias. Sin embargo, gozó de gran popularidad en la misma por sus cualidades personales y buen juicio. Participó en las Comisiones de Exa- 
men de listas de empleados; Comercio y Marina; de Marina y en la Inspección del Diario de las Cortes. Como los diputados progresistas americanos, se sitúa en las discusiones y votaciones junto al grupo dirigente de ellos, integrado por el ecuatoriano José Mejía Lequerica, los mexicanos Guridi y Alcocer y Ramos Arizpe y los centroamericanos Antonio Larrazábal y Florencio del Castillo. Así su voz se deja oír con la bancada americana en la discusión sobre igualdad de representación, y cuando por sorteo debe abandonar la Asamblea uno de los suplentes, en suerte es él el escogido para hacerlo. El reconocimiento de sus compañeros de Asamblea se hace sentir: al día siguiente de su salida se mandó expedir una certificación honorífica a su favor y su nombre fue mencionado para un puesto en el Consejo de Estado.

El papel de Manuel de Llano es mucho más importante. Desde la primera sesión se alinea con los liberales y al dia siguiente toma posición con los americanos en su facción. Es elegido inmediatamente para varias Comisiones: forma del decreto de publicación en América de la instalación de las Cortes; Colegio de Cirujía Médica; libertad individual; Premios y Honores; Diario de Cortes, en la que sustituye a su hermano. Y en el mes de abril de 1812 fue electo secretario de las Cortes.

Su voz se dejó oír muchas veces en la Asamblea como uno de los diputados más activos. Se pronuncia en favor de la libertad de imprenta y participa importantemente en la discusión sobre igualdad de representación. Pero es en la Comisión de Guerra donde presta servicio eminente, lo que se explica por su condición de militar profesional, que había realizado sus estudios en el famoso Colegio Militar de Segovia, de donde era graduado como ingeniero militar. En problemas referentes a la organización del ejército sobresale como un técnico, emitiendo caudalosamente opinión sobre múltiples aspectos: establecimiento de hospitales, depósitos y almacenes; fabricación de fusiles; contra privilegios internos; recompensas; Consejos de guerra; moral de tropa; ascensos, fuero militar; código militar; organización de Estados Mayores; clases de tropa y especialización de armas. En todas sus intervenciones sobre el tema se orienta hacia una liberalización y democratización del ejército sobre la base de una disciplina sin despotismo. MARIO RODRÍGUEZ (1984, pág. 99) llama la atención sobre que «este oficial guatemalteco trabajó asiduamente por las reformas militares, una inesperada contribución que Centroamérica aportó al experimento de Cádiz».

Pero su más importante propuesta se refiere a la libertad individual. El Derecho constitucional guatemalteco debe reivindicar un antecedente poco estudiado sobre la institución del habeas corpus, el primero en América Latina. Llano propuso el 14 de diciembre de 1810 que se nombrara una Comisión que se ocupara de redactar «una ley al tenor de la del habeas corpus que rige en Inglaterra que asegure la libertad de los ciudadanos". Seguido el trámite parlamentario, su proposición se integró al Título V de 
la Constitución que se refiere al Poder Judicial (Cfr. GARCIA LAGUARDIA, 1983, págs. 26-28; BARRAGÁN, 1978, págs. 79-108).

\section{EL DIPUTADO PROPIETARIO POR GUATEMALA DON ANTONIO DE LARRAZÁBAL}

\section{Labor parlamentaria}

Había nacido en 1779 y se incorpora muy joven a las Cortes. Nacido en la capital de Guatemala de ascendientes vascos, había tenido una cuidadosa educación religiosa y universitaria. Al momento de su elección era canónigo penitenciario, y desempeñó importantes cargos religiosos y públicos en su larga y activa carrera antes y después de su experiencia gaditana (Cfr. BRAÑAS, 1969).

Tres meses después de su elección, parte a un largo viaje de varios meses para España, deteniéndose en Oaxaca, México, Jalapa y Londres, y juró su cargo el 24 de agosto de 1811. Mantuvo una permanente comunicación con el ayuntamiento de Guatemala, y desempeñó cargos importantes: fue presidente de las Cortes electo dos meses después de haberse incorporado a las mismas; de los 37 presidentes diez fueron americanos y dos centroamericanos, el propio Larrazábal y el costarricense Del Castillo. Participó en la Comisión encargada de examinar la proposición del diputado Power, de Puerto Rico, sobre los abusos del gobernador de su provincia; en las de Honor, Ultramarina, Seminario de Canarias, Justicia, Asuntos Eclesiásticos y fue miembro de la Diputación Permanente, electo en condiciones especiales por unanimidad.

Su actividad fue impresionante, avalada por una puntualidad que le gustaba subrayar. Su trato distinguido, su personalidad cautivadora, su proporción en política, la firmeza de sus intervenciones le hicieron adquirir prontamente un puesto de primera fila en la Asamblea. No era una personalidad con dotes deslumbrantes; no era orador fogoso, sino más bien un parlamentario asentado, que argumentaba académicamente; algunos de sus discursos son verdaderas piezas de oratoria parlamentaria. De Labra afirma que «la intervención de Larrazábal fue la de discutir la política de principios, separándose de la política menuda», y establece un honroso parangón al decir que se asemejaba mucho en los problemas que trataba a Muñoz Torrero y Pachón (1912, págs. 78-79).

Su labor parlamentaria fue encomiable. Participó en la discusión del proyecto de Constitución que comenzaba a conocerse cuando se integra a la Asamblea urespecto del cual pronunció 27 discursos» (LABRA, 1912, pág. 
74). Y su participación es caudalosa en una gran variedad de asuntos que tenian relación con la organización general de la nueva monarquia constitucional española, con los asuntos americanos, con los de su propia provincia y con los de la organización religiosa. Una breve relación es la siguiente: promulgación de leyes; limitación de las facultades del rey; defensa de la libertad de imprenta; gobierno de las provincias impulsando la descentralización a través de las diputaciones provinciales y autonomia municipal; libertad económica como principio general, especialmente defensa de libertad de comercio sobre la que pronunció un excelente discurso; supresión de estancos y monopolios; defensa del fuero religioso y de varias reivindicaciones de la iglesia; defensa de derechos de prisioneros; igualdad de representación; derechos políticos de las castas; defensa de los indios proponiendo la abolición de las mitas apoyando a su compañero Castillo; educación de los indigenas; proposiciones sobre régimen electoral; administración de justicia, manifestando opinión contra penas infamatorias y a favor de igualdad de penalidad entre nacionales y extranjeros; sobre infracciones a la Constitución y penalidades; reformas económicas propiciando el reparto de tierras; medios para organizar escuelas necesarias para lograr la alfabetización; reglamento del Poder Ejecutivo; función del estandarte real; reemplazo del Consejo de Estado; derrota de Castilla; gobierno canónico de las provincias; traslado de las Cortes; representación del Consulado de México... Hasta lo vemos ocuparse del archivo de las Cortes y de la reimpresión de actas. Y puntual con su Universidad, hizo conocer a la Asamblea la tesis de graduación que Ignacio de Aycinena presentó en San Carlos sobre la Constitución en diciembre de 1813.

En el asunto del gobierno de las provincias fue especialmente diligente. La preocupación por la descentralización, el gobierno autónomo y el desarrollo económico le hizo ser reiterativo en la defensa de las diputaciones provinciales, que en el fondo significaban la institucionalización de las viejas Sociedades Económicas de conocida experiencia en la $\mathrm{Ca}$ pitania. Larrazábal, como muchos de los diputados americanos, cifraba esperanzas en estas nuevas instituciones y pretendia dotarlas de un poder político real y no meramente consultivo, como contrapeso a las atribuciones de los jefes políticos, lo que la bancada española neutralizó por sospechas de federalismo. Aprovechando una comunicación del Ayuntamiento, abrió de nuevo el debate sobre el tema, aunque ya había sido aprobado el articulado del proyecto constitucional en febrero de 1812, y propuso enmiendas sin éxito al artículo 335 aprobado, orientadas a una mayor fortaleza de las diputaciones ampliando sus atribuciones. (Para un análisis detallado de estos y otros puntos, cfr. GARCÍA LAGUARDIA, 1976, págs. 198-219; RODRÍGUEZ, 1978, págs. 79-107, y BERRUEZO, 1986, págs. 201-207.) 


\section{Las instrucciones al diputado}

La participación centroamericana en Cádiz dio ocasión a que el fermento ideológico que existía en la Capitanía aflorara. Los documentos que Larrazábal - probablemente el diputado mejor asesorado- lleva al constituyente suponen un ejemplo de seriedad y competencia que nos permite ubicar las tendencias del pensamiento político de la región y recoger las fuentes ideológicas diversas que están en la base de la futura organización republicana: la ilüstración francesa y el liberalismo inglés.

El Ayuntamiento de la capital elabora bajo la dirección de José María Peynado -en 1810- unas Instrucciones en las cuales el pensamiento político de la ilustración francesa se transparenta con claridad. Se incluía en ellas una Declaración de Derechos del Hombre y un Proyecto de Constitución de 112 artículos, junto a múltiples consideraciones de orden económico y fiscal. Como el grupo de comerciantes que integraba la minoría del cuerpo municipal no estuvo de acuerdo con la tendencia radical del documento elaboró un voto razonado, los Apuntes Instructivos, en el que se confesaba la influencia de la "Constitución inglesa». Y fuera de otras instrucciones menores el Consulado de Comercio formuló unos Apuntamientos para Larrazábal, que constituyen la radiografía más completa de la estructura social y económica de la región en los albores del siglo XIX. (Una edición facsimilar de los tres documentos en GARCÍA LAGUARDIA, 1971.)

Las Instrucciones - no sólo el Proyecto Constitucional y la Declaración de Derechos- tienen una gran importancia para una correcta elaboración e interpretación de la historia de las ideas e instituciones centroamericanas. En el límite del «antiguo régimen» y con claras influencias de las ideas del siglo XVIII francés, ataca a fondo el "despotismo» del régimen español y propone como solución política a la crisis la adopción de una Constitución, de un texto escrito que viniera a limitar el poder de los gobernantes, reconociendo un catálogo de derechos humanos y fijando un sistema de competencias circunscritas para el ejercicio del poder. La huella francesa es inequívoca. La última parte del documento está encabezada con un epigrafe de Montesquieu: «Todas las instituciones humanas tienen el sello del siglo en que se hicieron».

Entre líneas, se percibe que los autores tienen bien claro el esquema de las formas de gobierno de este autor, y que dentro de ellas han clasificado el régimen español como un auténtico despotismo, el gobierno de uno solo, sin normas que lo controlan y basado en el terror de los súbditos. El Capitán general Bustamante y Guerra - siempre tan lúcido-, en las anotaciones que aparecen en el ejemplar enviado a España para el proceso de Larrazábal, se dolía: «Los escritores extranjeros que más han deprimido la gloria de la peninsula, Rainal y Maison, no han hecho de España un cuadro tan negro" (Cfr. AGI, 1812, Legajo 497). Y como un remedio contra 
ese despotismo proponía el mágico remedio decimonónico: la promulgación de una Constitución: "Una Constitución, pues, que prevenga el despotismo del jefe de la nación; que señale los límites de su autoridad; que haga del Rey un padre y un ciudadano; que forme del magistrado un simple ejecutor de la ley; que establezca unas leyes consultadas con el derecho natural, que contiene en si todas las reglas de lo equitativo y lo justo, y que se hallen revestidas de todos los caracteres de bondad absoluta y de bondad relativa a los objetos primarios de la sociedad; que enseñen a los pueblos sus deberes; que circunscriban sus obligaciones; y que a éstas y a sus derechos señalen límites fijos e inalterables; que establezcan una administración clara, sencilla y cimentada en los principios de propiedad, libertad y seguridad; que bajo tales principios e ilustradas con la filosofía guarden proporción entre los delitos y las penas, y no establezcan otras que las absolutamente necesarias y útiles a la sociedad. Un sistema económico y político que auxilie los tres grandes principios de propiedad, libertad y seguridad. Una instrucción pública y metódica que disipe la ignorancia de los pueblos, y que difundiendo las luces promuevan la utilidad general's.

$Y$ con base en las ideas modernas de pacto social y estado de naturaleza de corte iusnaturalista, proponen una Declaración de Derechos del Hombre: «... hace la declaración solemne de ellos, señala los límites de sus obligaciones, los de las autoridades, los de la ley, y establece la Constitución sólida, permanente e inviolable». La raiz francesa es clara. La fuente directa del Derecho constitucional centroamericano, la formulación de la parte dogmática de los primeros documentos constitucionales, los encontramos en el pensamiento político francés del siglo XVIII, lo que es reconocido expresamente por sus autores (cfr. AGI, 1816 a, Audiencia de Guatemala, Leg. 502).

En el Proyecto de Constitución se recoge la parte orgánica del nuevo sistema propuesto. De 112 articulos, es el primer proyecto de un texto fundamental que se formula en Centroamérica y propone una Monarquía constitucional moderada (art. 7 y siguientes). Sin estridencia, adopta la teoría de la división de poderes, atribuyendo al soberano la facultad ejecutiva, y a la «Nación», la legislativa (art. 20) y sienta las bases de una Administración de justicia independiente (art. 21). Crea un Consejo Supremo Nacional “en el que residirá toda la representación de la Nación española y tendrá el Poder Legislativo en toda su extensión de los Códigos civil y criminal, político y económico" (art. 39), cuyos miembros serian designados por los ayuntamientos en los que se concentraba la fuente del nuevo régimen. Distingue entre poder constituyente originario y constituido, y propone un sistema de descentralización que se haría efectivo a través de juntas locales en cada capital del reino a fin de que "la máquina del gobierno no salga complicada y tenga en todas sus partes los resortes y muelles convenientes a fin de que por la suma distancia no pierdan las provincias su vigor y elasticidad». Con un encomiable sentido de pedagogía política, ordena la 
formación de un «catecismo» en el que se expliquen sencilla y claramente los principios del nuevo régimen constitucional «...para que los niños lo den de memoria y se les explique en las escuelas de primeras letras un día a la semana».

Proponía la organización de una Monarquía constitucional adoptando los nuevos principios: soberanía nacional temerosamente formulado, división de poderes claramente esbozado, idea del poder constituyente originario atribuido a las Cortes representando a la Nación. Y este marco teórico liberal se ve atemperado por los propios intereses de los actores, que orientaban el centro del poder a los ayuntamientos, controlados por los protagonistas del proyecto.

En la anotación final al ejemplar que Bustamante y Guerra envió a España sitúa el contenido del documento: «Esta es la Constitución del Ayuntamiento de Guatemala, que de tiempo inmemorial ha estado estancado en las familias de los americanos que la firman. De ella resulta que en sus artículos se deprime la autoridad del rey, se exalta la de los Ayuntamientos; que los Ayuntamientos son los que debían nombrar a los individuos de las Juntas serenisimas en quienes debian residir el gobierno de cada provincia en todos sus ramos y el derecho de informar para la provisión de empleos; que los Ayuntamientos debían hacer la elección de los individuos del Consejo Supremo Nacional en el que debia estar el Poder Legislativo, Ejecutivo y de dar todos los empleos políticos, militares y eclesiásticos; que los Ayuntamientos de América, mayores en número que los de España, eran, por consecuencia, el centro de las autoridades que habian de dictar leyes, proveer los empleos, gobernar la Monarquía y administrar las provincias; que a este respecto la soberanía quedaba realmente en la América cuando su situación era tan crítica...». Existe una contradicción entre los principios democráticos de la Declaración de Derechos y las limitaciones aristocráticas del Proyecto constitucional, la cual es percibida por José Cecilio del Valle (El Amigo de la Patria, 3 de noviembre de 1820), quien argumenta más tarde -en polémica contra el grupo de las «familias»- con gran lucidez: «En 1811 se publicaron las Instrucciones en la isla de León y el mismo año se dio en Cádiz el Proyecto de Constitución política de la Monarquía española. El sistema de las primeras consistía en que regidores elegidos no por el pueblo sino por los Ayuntamientos elijan a los alcaldes, síndicos y regidores, a los individuos de la Diputación provincial y diputados a Cortes. El sistema del segundo supone que el pueblo elija alcaldes, regidores, síndicos, individuos de la Diputación provincial y diputados a Cortes. Si el año 1811 era tiempo de ideas aristocráticas, ¿cómo en el mismo año se publicaron democráticas en el Proyecto de Constitución sancionada por las Cortes? Decir en la Declaración de los Derechos del Ciudadano que la legislatura es propiedad de la Nación, y querer en la Constitución que los diputados a Cortes no sean elegidos por el pueblo; decir que los derechos del ciudadano son la libertad y la igualdad, y privar al pueblo aún el de elegir regidores y alcaldes; decir que todos son iguales y libres, y sujetar 
a todos a la más dura aristocracia; éste es un fenómeno que por nuestro amor a Guatemala sentimos que se haya visto en Guatemala" (PANTOJA MORÁN y GARCÍA LAGUARDIA, 1975, págs. 23-38, hacen un detallado análisis del documento en el cual las fuentes españolas son omisas).

Debe anotarse la disidencia de los Apuntes Instructivos de la minoría. Si en el documento oficial de la mayoría, la raíz francesa es evidente, en el voto de la minoría se confiesa una influencia inglesa, en un esfuerzo vano de presentarse moderados frente a los otros. Apuntan haber tenido «no otro modelo que la Constitución inglesa... hallar, ordenar y fijar estos contrapesos al poder monárquico, en unos términos que lo equilibran y no lo destruyan; que lo obliguen a caminar por un carril demarcado, sin hacerle violencia...; fuera de esta razón para escoger el de la Constitución inglesa, nos impulsaban al propio efecto el honor mismo de nuestra antigua, que si no pudo, o no tuvo oportunidad para ordenarlos y fijarlos, reconoció al menos antes que aquélla y usó separadamente de los contrapesos». En común posición con los conservadores españoles, oponen la Constitución histórica y el ejemplo de Inglaterra, al desborde revolucionario democrático, preocupados por la «fatal pendiente que advertíamos hacia la democracia, aun en los mismos que sólo se proponen contener la arbitrariedad de un monarca».

Los documentos fueron conocidos en Cádiz antes de que la Constitución de 1812 fuera promulgada, pero es improbable que influyera en su redacción, aunque Bustamante hizo hincapié en el influjo que habia tenido en la española y el Consejo de Indias llamó la atención en la semejanza del articulado (AGI, 1817, Audiencia de Guatemala, Legajo 502).

Lo que sí puede afirmarse es que el Proyecto fue conocido por la Comisión de Constitución en Cádiz antes de que terminara su trabajo. Ésta presentó su proyecto en tres partes: el 18 de agosto, el 6 de noviembre y el 20 de diciembre de 1811. Larrazábal tomó posesión el 25 de agosto del mismo año, cuando ya se había presentado la primera parte, entrando en contacto inmediatamente con los miembros de la Comisión, según informa el Ayuntamiento de Guatemala, y afirma que los miembros de la Comisión las tuvieron presentes al formar la segunda y tercera partes, pero se duele de la indiferencia de los peninsulares porque «... habiéndose tenido a la vista dichas instrucciones de este Ayuntamiento y otras proposiciones que hizo el señor diputado de León, de Nicaragua, don José Antonio López de la Plata... el Congreso no las ha admitido..." (BAGG, 1938 b, n. ${ }^{\circ}$, pág. 50). En las Actas de la Comisión de Constitución, en efecto, no se hace ninguna referencia ni al proyecto guatemalteco ni al diputado Larrazábal, y solamente en el acta de la sesión del 17 de septiembre se recoge la intervención de López sobre igualdad de representación, que no fue admitida (cfr. Actas, 1976). 


\section{Destino final del diputado Larrazábal y de los documentos}

La Restauración de Fernando VII significó la vuelta al absolutismo, disolución de las Cortes y desconocimiento de la reforma intentada. Se ordenó el arresto de los diputados considerados más importantes y peligrosos, y entre ellos se incluyó a Larrazábal. Lo que parecía natural, dada su firme posición liberal y su entereza en la defensa del nuevo orden constitucional. Trasladadas las Cortes a Madrid, era muy enfático en llamar la atención en las infracciones a la Constitución. En enero de 1814, días antes de la Restauración, las galerías se entusiasmaron ante las intervenciones de Larrazábal y Canga-Argüelles, y por la noche, según recoge la prensa, una estudiantina ofreció una serenata al diputado por Guatemala (cfr. Redactor General, 18 de enero de 1814).

Después de un regateo burocrático, en el que varios funcionarios quisieron eludir responsabilidad, se dictaron condenas para un grupo de los detenidos. En la Real Orden de 17 de diciembre de 1815 se condena a cinco diputados a diversas penas. A Larrazábal, el único centroamericano, a seis años de reclusión en el convento que señalara el arzobispo de Guatemala, para que bajo su dirección se dedicara a «aprender religión y fidelidad a su rey". Y así comienza un viacrucis: tres años en Cádiz; un viaje riesgoso; estancia - más de huésped que de recluso- en el convento de la Orden de Belén, en La Habana, para entrar a la ciudad de Guatemala, en calidad de preso, el 16 de abril de 1819, con destino al convento de Belén, de donde salió en el año 1820 como resultado de la nueva revolución española.

No mejor suerte corrieron la Declaración de derechos y el Proyecto constitucional, que desde sus origenes fueron vistos con desconfianza. Bustamante - el famoso Capitán General- percibió desde un principio el fondo ideológico del documento y su connotación subversiva. Característico, tenaz, laborioso - no bien la Restauración se lo permite- se dirige al rey, inquisitorialmente, en persecución del documento, y envía un ejemplar del mismo con significativas anotaciones. Agudamente observaba las consecuencias de su adopción: "un sistema en que debian quedar el Poder legislativo en manos de los americanos elegidos en Indias, cuyo número debía ser mayor que el de los españoles; el gobierno de América en Juntas compuestas también de americanos y la Administración real de la Hacienda en los Ayuntamientos, es un sistema de positiva insurrección; un sistema de verdadera independencia, propio para cortar las relaciones de España y sus Indias". Conmovido, el Rey dicta Real Orden condenatoria. En las Instrucciones, afirmaba, se copiaban a la letra muchas proposiciones de la Asamblea Nacional de Francia, y habia encendido la tea de la discordia y la revolución. Debian recogerse todos los ejemplares que existieran de ella y además los que la firmaron quedarían incapaces de obtener «empleo alguno" en América. Oficiosas, las autoridades locales cumplieron con lo 
ordenado, haciendo una recolección de los ejemplares existentes y papeles que a las Instrucciones se referían, y al final del año 1815 se llevó al límite la voluntad real, llevándola a la hoguera pública en la plaza Mayor. Bustamante informaba satisfecho: «La citada Instrucción ha sido quemada en esta capital por mano del pregonero en falta de ejecutor público el día 22 de diciembre último...» (cfr. AGI, 1816 b, Audiencia de Guatemala, Leg. 502).

\section{EL RESTO DE LA DIPUTACIÓN CENTROAMERICANA}

Al lado de Larrazábal, el diputado Florencio del Castillo destaca en la Asamblea. Nacido en Ujarraz, en Costa Rica - donde vivió muy pocos años-, se formó en el prestigioso Seminario de León, en Nicaragua, del que fue catedrático y vice-rector y después de su experiencia gaditana se radicó en México, en el estado de Oaxaca, desempeñando importantes cargos religiosos y políticos; cuando muere era gobernador de la Diócesis del estado.

Laborioso, integró varias Comisiones importantes en las Cortes: Honor, Ultramarina, Asuntos Atrasados, Justicia, Americana, Comisión Extraordinaria de Hacienda y Sanidad. Y sobresalió como uno de los mejores oradores de la Asamblea. Fue distinguido con cargos de dirección: secretario, vicepresidente y presidente de las Cortes.

En cinco áreas puede reseñarse su brillante participación parlamentaria. En la lucha por el control político de la Asamblea, destaca en la defensa de la igualdad de representación entre España y América; en el ataque a los privilegios; en la búsqueda de autonomía del gobierno de las provincias, y en la propuesta de múltiples reformas locales para la provincia que representaba. Más independiente que Larrazábal de la jerarquía eclesiástica, vota por la supresión del Tribunal de la Inquisición e incluso firma el Manifiesto en que se exponen los motivos de su abolición.

Pero es en la defensa de las clases menos privilegiadas en la que sobresale. Pugnó porque se otorgara el derecho de ciudadanía a las castas y aunque esto no se logró propuso que se facilitara su acceso al sistema educativo. $Y$ en cuanto a los indios, se convierte en su adalid. En abril de 1812 presentó seis proposiciones en su defensa en las que proponía la abolición de las mitas y las encomiendas; la prohibición del trabajo personal a los curas como obligación o sustitución de los tributos que debían a la iglesia; que las cargas públicas se repartiesen proporcionalmente entre los vecinos; necesidad de repartición de la tierra para fomentar la agricultura, planteando así la idea de la reforma agraria; eliminación de la servidumbre personal y obligación de pago en dinero y, finalmente, facilidades de acceso a los seminarios conciliares (cfr. ARMELLADA, 1959, y GARCIA LAGUARDIA, VOLIO y MELÉNDEZ, 1987).

El papel de los otros diputados es menos relevante pero igualmente importante $y$, en general, se centró en reivindicaciones de sus respectivas 
provincias. Robles de Mazariegos, quien sustituye a Manuel de Llano por Chiapas, presenta una extensa Memoria sobre la provincia en la que se denunciaban las injusticias contra la población indígena y se proponían reformas consideradas necesarias y supresión del perjudicial monopolio del tabaco; solicitó la constitución del seminario conciliar, universidad, apertura de nuevos puertos y construcción de un canal por Tehuantepec.

De Ignacio Ávila es del que se tiene menos información. Interviene en las Comisiones de Examen de Memoriales, Honor y Hacienda, y propugna por la creación de un obispado y un seminario conciliar en su provincia salvadoreña, además del fortalecimiento de la autonomía municipal. Francisco Morejón, abogado cuidadosamente formado en la Universidad de Guatemala, participa en la discusión de la organización de la Administración de justicia, y presenta once proposiciones en favor de Honduras, en general orientadas al desarrollo económico y especialmente minero. El nicaragüense López de la Plata se integra en varias Comisiones: de $\mathrm{Ne}-$ gocios Ultramarinos, Justicia, Manifiesto de la Central, Tribunal de Cortes, Ultramarina y Honor. En julio de 1813 es electo vicepresidente de la Asamblea. Se alineó con la Diputación americana y con la de la Capitanía en asuntos de carácter general y fue también muy celoso en plantear reivindicaciones de su provincia, solicitando una Capitanía General y una Diputación provincial que abarcara a Costa Rica y Nicaragua y la creación de una Universidad en León de la misma categoria que la de San Carlos en la capital, de vieja prosapia. (Sobre la actuación de estos diputados, cfr. VOLIO, 1980, passim; BERRUEZO, 1986, págs. 194-221, y BERRUEZO, 1988, págs. 35-69.)

\section{VISIÓN GENERAL}

La Diputación centroamericana en las Cortes fue muy homogénea y en su integración confluyeron diversas profesiones complementarias: dos militares, tres eclesiásticos y tres abogados. La excelente formación de los electos contribuyó a que su presencia en la Asamblea fuera relevante para afrontar los diversos problemas que el nuevo orden constitucional contemplaba. Berruezo, después de analizar la participación de todas las delegaciones de las provincias de América, afirma que la de Guatemala sobresalió entre todas "porque se dio en ella la coincidencia de existir un equilibrio entre la extracción profesional de sus componentes y la consiguiente especialización que aquélla les ofreció en conocimientos y estudios" (1986, pág. 304). Y en ella sobresalió la participación de Larrazábal, por la amplitud de la temática sobre la que se pronuncia, el asesoramiento que se le ofreció y su característica personalidad. 
En bloque, la fracción centroamericana se adscribe al grupo liberal reformista, que pugna por una Monarquía constitucional moderada y por profundos cambios en el aspecto económico y social. El pensamiento de la ilustración, en el cual todos sus integrantes habian sido formados, encuentra en las Cortes y su profundo contenido de reforma un cauce por donde expresarse.

Pretendía mantener la unidad de las colonias con la metrópoli, a través de un nuevo arreglo en el cual se vieran satisfechas las pretensiones de reforma y mejora de las provincias americanas. Al no ver satisfechas por los peninsulares estas demandas, y con motivo de la abolición de la Constitución en 1814 y el regreso de Fernando VII que permitió a Bustamante y Guerra endurecer su posición contra las nuevas instituciones y sus adalides locales, se abre paso una opinión en favor de la independencia.

A diferencia de otras regiones americanas en las cuales el movimiento de independencia adquirió connotaciones violentas, en la Capitanía de Guatemala - lo que hoy integran los cinco países centroamericanosel experimento de Cádiz se vio con gran esperanza. A pesar de la grave recesión económica y la negativa actitud regionalista que se oponía a la implantación de la reforma, los guatemaltecos con entusiasmo se abocaron a ella, con la tenaz oposición de Bustamante. Y la Constitución se aplicó en sus dos periodos, 1814 y 1820 , a pesar de la resistencia encubierta de las autoridades peninsulares. Con el marco del pensamiento de la ilustración, una confluencia entre el liberalismo metropolitano y provincial, que se rompe más tarde al precipitarse la independencia en 1821. 


\section{REFERENCIAS BIBLIOGRÁFICAS}

\section{Libros:}

Actas de la Comisión de Constitución (1811-1813). Estudio preliminar por M. ${ }^{a}$ CRISTINA DIz-LoIS; coordinador, Federico Suárez. Madrid, Instituto de Estudios Pòlíticos, 1976.

Armellada, Fray Cesáreo de: La causa indígena americana en las Cortes de Cádiz. Madrid, Instituto de Estudios Políticos, 1959.

ARTOLA, Miguel: Los origenes de la España contemporánea. Madrid, Instituto de Estudios Políticos.

BarRagan, José: Temas del liberalismo gaditano. México, Universidad Nacional Autónoma de México, 1978.

Berruezo, Maria Teresa: La participación americana en las Cortes de Cádiz, 1810-1814. Madrid, Centro de Estudios Constitucionales, 1986.

Brañas, César: Antonio Larrazábal, un guatemalteco en la historia. Guatemala, Imprenta Universitaria, 1969.

Garcia Laguardia, Jorge Mario: Las Cortes de Cádiz y la Constitución de 1812. Guatemala, Editorial Universitaria, 1967.

-: Génesis del constitucionalismo guatemalteco. Guatemala, Imprenta Universitaria, 1971.

-: Origenes de la democracia constitucional en Centroamérica, 2. ${ }^{a}$ ed., San José de Costa Rica, Editorial Universitaria Centroamericana, 1976.

- La defensa de la Constitución. Guatemala, Facultad de Ciencias Jurídicas y Sociales de la Universidad de San Carlos de Guatemala e Instituto de Investigaciones Jurídicas de la Universidad Nacional Autónoma de México, 1983.

Garcia Laguardia, Jorge Mario; Marina Volio y Carlos Melendez Chaverry: La Constitución de Cádiz y su influencia en América (175 años, 
1812-1987). San José de Costa Rica, Centro Interamericano de Asesoría y Promoción Electoral, 1987.

JiMENEZ de Gregorio, Fernando: La convocatoria de Cortes Constituyentes en 1810. Estado de la opinión española en torno a la reforma constitucional. Plasencia 1936.

LABRA y CADRANA, Rafael Maria de: Los presidentes americanos en las Cortes de Cádiz. Estudio biográfico. Cádiz, Imprenta de Manuel Alvarado Rodriguez, 1912.

Pérez Guilhow, Dardo: La opinión pública española y las Cortes de Cádiz frente a la emancipación hispanoamericana, 1808-1814. Academia Nacional de la Historia, 1981.

Rodriguez, Mario: El experimento de Cádiz en Centroamérica, 1808-1826. México, Fondo de Cultura Económica, 1985.

Volıo, Marina: Costa Rica en las Cortes de Cádiz. San José de Costa Rica, Editorial Juricentro, 1980.

\section{Revistas:}

BerRuezo León, Maria Teresa: «El funcionariado americano en las Cortes gaditanas, 1810-1813" Cuadernos hispanoamericanos (España), 460, págs. 35-69, 1988.

Boletin del Archivo General del Gobierno: «Año de 1809. Elección de diputado del M. N. y L. Ayuntamiento de esta ciudad de Santiago de los Caballeros de Guatemala para la Suprema Junta Central Gubernativa de España e Indias» (Guatemala), año II, número 3, págs. 383$388,1938$.

Boletín del Archivo General del Gobierno: «El diputado Larrazábal acusa recibo de ciertos documentos que le envió el Ayuntamiento y da cuenta de la marcha de las Cortes Generales en comunicación de fecha 31 de enero de 1813» (Guatemala), año III, núm. 4, página 50, $1938 b$.

Boletín del Archivo General del Gobierno: «M. N. Ayuntamiento. Año de 1810. Elección de diputados para las Cortes convocadas para la Isla 
de Mallorca por el Real Decreto de 29 de enero del corriente año" (Guatemala), año III, núm. 4, págs. 475-480, $1938 \mathrm{c}$.

Comellas, José Luis: «Las Cortes de Cádiz y la Constitución de 1812», Revista de Estudios Políticos (España), núm. 126, págs. 64-112, 1962.

GaRCIA LAGUARDIA, Jorge Mario: «Estado de la opinión sobre convocatoria a Cortes Constituyentes en 1810. La posición del Ayuntamiento de Guatemala", Antropología e Historia (Guatemala), núm. 1-2, págs. 77-90, 1969.

KING, James Ferguson: "The colored castas and american representation in the Cortes of Cadiz», The Hispanic-American Historial Review (Estados Unidos), núm. 33-1, págs. 33-64, 1953.

Ramos, Demetrio: "Las Cortes de Cádiz y América", Revista de Estudios Políticos (España), núm. 126, págs. 433-640, 1962.

\section{Documentos}

Archivo General de Indias (Sevilla), Guatemala, 493. «Representación del capitán general González Mollinedo informando al secretario de Estado y del Despacho Universal de Gracia y Justicia, fechada el primero de enero de 1810 , sobre lo practicado y estado de la elección de diputado a la Junta Central».

A.G.I. (Sevilla), Guatemala, 502. "Representación de don José María Peynado al Rey, de fecha 31 de enero de 1816, pidiendo se suspenda el cumplimiento de la orden de 31 de marzo de 1815, por la que se la he desposeído de sus destinos", 1816 a. 
A.G.I. (Sevilla), Guatemala, 502. «Representación del capitán José de Bustamante al secretario de Estado y del Despacho Universal de Indias, de 3 de enero de 1816", $1816 b$.

A.G.I. (Sevilla), Guatemala, 502. "Dictamen sobre las Instrucciones del Ayuntamiento de Guatemala, del Consejo Pleno de Indias, a 28 de febrero de 1817", 1817.

A.H.N. (Madrid), Sección de Estado, Legajo 20, Letra L, Expediente 7, «Representación del Ayuntamiento de Guatemala a la Junta Central sobre convocatoria a Cortes, de fecha 30 de enero de 1810», 1810.

\section{RECOMENDACIÓN DE LECTURAS ADICIONALES}

La bibliografía sobre las Cortes de Cádiz es amplísima y permanentemente se enriquece con nuevos aportes. Para completar su estudio es necesario consultar las fuentes y para eso el Diario de Sesiones es indispensable. Existen varias ediciones: Diario de las discusiones y actas de las Cortes (23 vols., Cádiz, 1811-1813), Diario de las Sesiones de las Cortes Generales y Extraordinarias (8 vols., Madrid, 1870) y también las Actas de las sesiones secretas de las Cortes Generales y Extraordinarias de la nación española (Madrid, 1874). Con un uso amplio de las fuentes, vid. MARTÍN FERNÁNDEZ, Derecho parlamentario español (3 vols., Madrid, 1885). Los estudios de los contemporáneos son claves: Juan Rico y AMAT, Historia política y parlamentaria de España desde los tiempos primitivos hasta nuestros días ( 3 vols., Madrid, Imprenta de las Escuelas Pias, 1861); Conde de TORENo, Historia del levantamiento, guerra y revolución de España (3 vols., París, Librería Europea, 1851), y Agustín ARgüELLES, Examen histórico de la reforma constitucional (2 vols., Londres, 1845). Buenos análisis recientes: Manuel FERnANDEZ ALmAGRo, Los orígenes del régimen constitucional en España (Madrid, Labor, 1928); Miguel ARTOLA, Los origenes de la España contemporánea (2 vols., Madrid, Instituto de Estudios Políticos, 1959), y Ramón Solis, EI Cádiz de las Cortes. La vida en la ciudad en los años de 1810 a 1813 (Madrid, Instituto de Estudios Políticos, 1958). Vicente Rocafuerte publica tempranamente en varios números del periódico Ocio de los españoles emigrados, publicación de los exiliados españoles en Londres, el primer análisis comparado de un grupo de constituciones americanas, las de México, Guatemala, Gran Colombia, Perú y Chile, en relación con la de Cádiz, subrayando la fuente directa que el constitucionalismo es- 
pañol tenía en el latinoamericano, «Examen analítico de las Constituciones formadas en Hispanoamérica", Revista de Historia de América (México), núm. 72, págs. 419-484.

El interés por el tema en Guatemala surge en 1939, cuando Sofonías Salvatierra, historiador nicaragüense, descubre en el Archivo de Indias en Sevilla las Instrucciones de Larrazábal, que son publicadas por los Anales de la Sociedad de Geografía e Historia, y de las cuales hace un análisis en Contribución a la historia de Centroamérica. Monografias documentales (2 vols., Managua, Tipografía El Progreso, 1939). César BRAÑAS las publica completas con un buen prólogo en 1953, centenario de la muerte de Larrazábal; Manuel VALLADARES RuBIO, en Estudios históricos (Guatemala, Imprenta Universitaria, 1962), incluye trabajos sobre los hermanos Llano y sobre Larrazábal, y antes, Francisco Fernandez Hall, en los Anales de la Sociedad de Geografía e Historia, en diciembre de 1928, había publicado un trabajo sobre "Las Cortes de Cádiz y la actuación del diputado en ellas».

De la bibliografía citada en la lista de referencias deben destacarse los trabajos de BerRuezo, Garcia laguardia, Volio y Rodriguez, quien en su excelente libro incluye un extenso capítulo especialmente útil, «Bibliografia» (1984, págs. 319-344). 